\title{
Risk Sharing of Urban Underground Comprehensive Pipe Gallery PPP Project Based on Grey Relational Analysis
}

\author{
Duan Shixia ${ }^{1, a}$, Diao Jielin ${ }^{1, b}$ \\ ${ }^{1}$ School of Management Engineering, Zhengzhou University, Zhengzhou, China
}

\begin{abstract}
In order to establish a reasonable, effective and accurate risk sharing mechanism for PPP project of urban underground comprehensive pipe gallery, 25 risk factors are identified by the work structure decomposition method. Secondly, a risk sharing method based on improved grey correlation analysis is proposed to solve the complexity of risk sharing in PPP project of urban underground comprehensive pipe gallery. Then, an improved risk sharing model is constructed based on this method. Finally, some targeted measures are proposed for the identified key risk factors. This risk sharing model has certain reference value for the research on risk sharing of urban underground comprehensive pipeline corridor PPP projects.
\end{abstract}

\section{Introduction and literature review}

The comprehensive pipe corridor generally refers to the public municipal pipelines that are built underground in cities to accommodate electricity, communications, water power, and heat. The construction period is long, the investment is large, and the risk is high. The construction completely funded by the government cannot meet the needs of major cities in China. There is an urgent need for the construction of underground comprehensive pipeline corridors, and the PPP model can obtain more social capital investment. In the construction of comprehensive pipeline corridors, the use of PPP model can effectively alleviate the pressure on government finances, and improve project management efficiency and reduce costs. In the construction of integrated pipeline corridors, the use of the PPP model may cause more instability due to the different interests of the participants. The government hopes that risks can be transferred appropriately, and the social capital hopes that risks and benefits match. The game between the parties This makes the problem of risk sharing more complicated, and reasonable risk sharing for the pipe gallery project is crucial to the success of the project.

Some scholars at home and abroad have done some research on PPP project risk sharing. Through the method of case analysis, Ke Yongjian Ke Yongjian [1] used the method of case analysis to extract the risks affecting the success of the PPP project and carried out a reasonable risk sharing ${ }^{1}$. Chen et al. pointed out the irrationality of PPP project risk allocation, which is currently mostly beneficial to the strong $\operatorname{side}^{2}$. Abednego based on the project participants' control, resolution and willingness to undertake the project, the project risk is reasonably shared $^{3}$. Li Shouguo et al. reasonably shared the project risks based on the project participants' control, resolution and willingness to undertake the project ${ }^{4}$. This article combines the characteristics of the pipe gallery project to make a more accurate calculation of risk sharing. First, identify the initial list of key risk factors of the PPP project, refer to the research on risk preference of risk-sharing researchers, establish a risk-sharing index system, and use the grey relational analysis method to solve it, so as to realize the reasonable sharing of risks in the index system.

\section{Risk Sharing Index System for PPP Projects of Urban Underground Comprehensive Pipe Gallery}

\subsection{Risk Identification}

To evaluate risks, we must first identify the risks, and then build a complete and hierarchical evaluation system based on the identified risks. This article reads through the literature, compares the advantages and disadvantages of various risk identification methods and the scope of application, uses the working structure decomposition method (WBS) to analyze the risks faced by the urban underground comprehensive pipeline corridor PPP project, and divides the possible risks of the project construction into two The main categories are the external risks caused by the environment in which the project is constructed, and the internal risks arising from the process of project construction. There are roughly three types of environment in which the project is constructed, namely the natural environment, the political environment, and the market environment. Environmental risks are not transferred by human will and cannot be prevented from occurring but can only be prevented in advance; from the perspective of project construction, the main risks are It originates from the organizational behaviors of various project subjects related to project construction. The project 
subjects mainly involve the government, private investors, construction units and operating units, among which the construction units themselves are faced with risks such as insufficient technology and poor management. Therefore, the main sources of risks faced by urban underground comprehensive pipeline corridor PPP projects are force majeure risks, political risks, market risks, supply risks, financial risks, project construction and completion risks, technical risks, and operational management risks. The following is a risk factor analysis of these 8 types of risks.

2.1.1 Political risk: Political risks refer to the risks of damage to PPP project assets and future cash flows due to wars, changes in international relations, and policy changes.

2.1.2 Force majeure risk: PPP projects also face the risk of force majeure. Risks include risks caused by typhoons, earthquakes, floods, and accidents. This type of risk is beyond the control of the project company. Once it occurs, it will cause immeasurable losses to the project.

2.1.3 Market risk: The complex market environment will have an impact on costs, and changes in product sales in the market and other conditions have brought huge market risks to the project.

2.1.4 Supply risk: The increase in the price of raw materials or energy, resources, or the shortage of supply of various supporting facilities that serve the project, and the untimely supply, all bring losses to the project.

2.1.5 Financial risk: Financial risk refers to the risk of losses incurred by construction units and operating units due to changes in interest rates, exchange rates, commodity prices and stock prices.

2.1.6 Project construction and completion risks: Project construction and completion risks refer to the risks of poor operation, poor sales, and cost overruns after the completion of the PPP project of the urban underground comprehensive pipeline gallery.

2.1.7 Technology risk: Technical risk is mainly the possibility that the final result of the project may deviate from the expected due to insufficient managerial ability or insufficient preparation. This part mainly involves human issues, including managers and construction personnel. Insufficient information held by managers can lead to misjudgments of prices and exchange rates. When the design is unreasonable and needs to be changed, the purchase plan also needs to be adjusted, which may lead to the need to repurchase materials and equipment, resulting in an increase in costs and an extension of the construction period.

2.1.8 Operation management risk: Various risks and losses caused by organizational and management issues during the construction, operation and maintenance of the project.

\subsection{Create a risk list}

Through the above analysis, the risk factors of the PPP project of the urban underground comprehensive pipeline gallery can be obtained, and on this basis, the risk list is established, and the corresponding evaluation system is established at the same time, as shown in Table 1.

Table1. PPP project risk list of urban underground comprehensive pipe gallery

\begin{tabular}{|c|c|c|}
\hline Type of risk & Source of risk & Risk factors \\
\hline \multirow{8}{*}{ External risk } & \multirow{2}{*}{ Political risk $E_{1}$} & Regime change $E_{11}$ \\
\hline & & Policy changes $E_{12}$ \\
\hline & \multirow{4}{*}{ Force majeure risk $E_{2}$} & Geological disaster $E_{21}$ \\
\hline & & Meteorological disaster $E_{22}$ \\
\hline & & Marine disaster $E_{23}$ \\
\hline & & Other accidents $E_{24}$ \\
\hline & \multirow{2}{*}{ Market risk $E_{3}$} & Product prices fluctuate greatly $E_{31}$ \\
\hline & & Significantly reduced demand $E_{32}$ \\
\hline \multirow{7}{*}{ Internal risk } & \multirow[t]{2}{*}{ Supply risk $E_{4}$} & $\begin{array}{l}\text { Increase in the price of raw materials required for the construction of } \\
\text { the pipe gallery project } E_{41}\end{array}$ \\
\hline & & Supplier delivery is not timely $E_{42}$ \\
\hline & \multirow{3}{*}{ Financial risk $E_{5}$} & $\begin{array}{l}\text { The capital chain was interrupted during the construction of the pipe } \\
\text { gallery } E_{51}\end{array}$ \\
\hline & & Large changes in interest rates $E_{52}$ \\
\hline & & inflation $E_{53}$ \\
\hline & \multirow{2}{*}{$\begin{array}{l}\text { Project construction and completion risks } \\
\qquad E_{6}\end{array}$} & Pipe gallery project cannot be completed on time $E_{61}$ \\
\hline & & Pipe gallery project cost overrun $E_{62}$ \\
\hline
\end{tabular}




\begin{tabular}{|c|c|c|}
\hline Type of risk & Source of risk & Risk factors \\
\hline & & The pipe gallery project technology is not good enough $E_{63}$ \\
\hline & & Excessive design changes of the pipe gallery project $E_{64}$ \\
\hline & \multirow{4}{*}{ Technology risk $E_{7}$} & Construction technology equipment is not applicable $E_{71}$ \\
\hline & & The technology used is not advanced $E_{72}$ \\
\hline & & Low resource utilization efficiency $E_{73}$ \\
\hline & & Inadequate training of construction personnel $E_{74}$ \\
\hline & \multirow{4}{*}{ Operation management risk $E_{8}$} & Lack of good communication between all parties to the project $E_{81}$ \\
\hline & & Imperfect management standards $E_{82}$ \\
\hline & & The maintenance cost of the pipe gallery project is too high $E_{83}$ \\
\hline & & The equipment is not up to standard after the handover $E_{84}$ \\
\hline
\end{tabular}

\section{Establishment of Risk Sharing Model for PPP Project of Urban Underground Comprehensive Pipe Gallery}

"Gray system" refers to a system with clear and partially unknown information, and there is no clear functional relationship between the various factors in the system. The incompleteness and asymmetry of market information fully meet the conditions of gray comprehensive evaluation. The comprehensive evaluation method of grey relational degree describes the relative changes of various index factors in an information matrix. The stronger the relation, the greater the degree of relation. The comprehensive evaluation method based on gray correlation is mainly divided into the following steps:

3.1.1 Based on the completion of the evaluation index system, the corresponding data is collected, and the 25 identified indicators are sorted according to certain standards to form a comparison series, which is recorded as a judgment matrix:

$$
X=\left[X_{1}, X_{2}, \ldots, X_{25}\right]=\left[\begin{array}{cccc}
x_{1}(1) & x_{2}(1) & \ldots & x_{25}(1) \\
x_{1}(2) & x_{2}(2) & \ldots & x_{25}(2) \\
\ldots & \ldots & \ldots & \ldots \\
x_{1}(m) & x_{2}(m) & \ldots & x_{25}(m)
\end{array}\right](1)
$$

3.1.2 Select the maximum score from the degree of influence gained as the reference value $x_{0}(k)$, the correlation degree $r_{i}$ is calculated by formula (2) and formula (3), where the resolution coefficient $\rho \in(0,1)$, usually take $\rho=0.5$, the weight $w_{i}$ is $r_{i}$.

$$
\xi_{i}(k)=\frac{\min _{i} \min _{k}\left|x_{0}(k)-x_{i}(k)\right|+\rho \max _{i} \max _{k}\left|x_{0}(k)-x_{i}(k)\right|}{\left|x_{0}(k)-x_{i}(k)\right|+\rho \max _{i} \max _{k}\left|x_{0}(k)-x_{i}(k)\right|}
$$

(2)

$$
r_{i}=\frac{1}{n} \sum_{k=1}^{n} \xi_{i}(k)
$$

However, in the application process, this method has certain shortcomings ${ }^{4}$ : First, there are many factors that affect the weighting results. For example, the selection of the reference value $x_{0}(k)$, the value of the resolution coefficient $\rho$, etc. will affect the calculation result of the correlation coefficient $\xi_{i}(k)$, thereby affecting the calculation result of the weight. The second is that the weights are less distinguishable. Since generally $\rho=0.5 \quad, \quad$ if $\quad\left|x_{0}(k)-x_{i}(k)\right|=a \quad$, $\min _{i} \min _{k}\left|x_{0}(k)-x_{i}(k)\right|=b$

$\max _{i} \max _{k}\left|x_{0}(k)-x_{i}(k)\right|=c$, then $r_{i}=\frac{b+0.5 c}{a+0.5 c}$; and $b \geq 0, c \geq 0$; if $a=c, r_{i}$ minimum, $r_{i}=\frac{b+0.5 c}{c+0.5 c}>\frac{0.5 c}{c+0.5 c}>0.333$. That is, the correlation degree $r_{i}$ is always greater than 0.333 , so the degree of discrimination of the weights will be small.

Therefore, this article adopts the improvement method of grey relational degree, based on the expert experience scoring method, obtains the evaluation index, and forms the evaluation matrix $X$; the maximum value is selected as the common reference value to form a reference series; the distance between each index and the reference series is obtained, and the weights are further solved and normalized. This method does not involve the setting of subjective values such as resolution coefficients, and to a certain extent ensures the subjectivity of expert scores, and objective calculations are carried out in the calculation process.

3.1.3 Using the expert experience scoring method, six experts in this field were invited to score the occurrence probability of the risk factors of the partners in the PPP project of the urban underground comprehensive pipeline corridor and the degree of harm of the risk factors, and set the score value according to Table 2. Table 3 shows the degree of influence of each risk factor calculated according to the expert score results. 
Table2. THE probability of occurrence of risk factors and the degree of harm of all parties involved in the PPP project of urban underground comprehensive pipeline gallery Likert five-point scale

\begin{tabular}{|c|c|c|}
\hline fraction & $\begin{array}{c}\text { Probability of risk } \\
\text { factors }\end{array}$ & $\begin{array}{c}\text { Risk factor harm } \\
\text { degree }\end{array}$ \\
\hline 1 & Very low probability & Irrelevant \\
\hline
\end{tabular}

\begin{tabular}{|c|c|c|}
\hline fraction & $\begin{array}{c}\text { Probability of risk } \\
\text { factors }\end{array}$ & $\begin{array}{c}\text { Risk factor harm } \\
\text { degree }\end{array}$ \\
\hline 2 & Low probability & Secondary \\
\hline 3 & Medium probability & General \\
\hline 4 & High probability & Large \\
\hline 5 & Very high probability & Very large \\
\hline
\end{tabular}

Table3. Calculation table of influence degree of risk factors of all parties to the PPP project of urban underground comprehensive pipeline gallery

\begin{tabular}{|c|c|c|c|c|c|c|c|}
\hline Source of risk & Risk factors & & & & re of e & ch exp & \\
\hline \multirow{2}{*}{ Political risk $E_{1}$} & Regime change $E_{11}$ & 3.87 & 3.87 & 5 & 4.47 & 4.47 & 3.46 \\
\hline & Policy changes $E_{12}$ & 3 & 3.46 & 4 & 4 & 3 & 3 \\
\hline \multirow{4}{*}{ Force majeure risk $E_{2}$} & Geological disaster $E_{21}$ & 4.47 & 5 & 4.47 & 3 & 3.46 & 3.46 \\
\hline & Meteorological disaster $E_{22}$ & 2 & 2.45 & 3 & 2 & 2 & 2.45 \\
\hline & Marine disaster $E_{23}$ & 1.41 & 1.73 & 1.41 & 2 & 1.73 & 2 \\
\hline & Other accidents $E_{24}$ & 1.73 & 1.73 & 1.41 & 1.41 & 2 & 1.41 \\
\hline \multirow{2}{*}{ Market risk $E_{3}$} & Product prices fluctuate greatly $E_{31}$ & 1.41 & 1 & 1 & 1.41 & 1 & 1 \\
\hline & Significantly reduced demand $E_{32}$ & 2.24 & 2.24 & 2.45 & 3 & 3.16 & 1.73 \\
\hline \multirow[t]{2}{*}{ Supply risk $E_{4}$} & $\begin{array}{l}\text { Increase in the price of raw materials required for } \\
\text { the construction of the pipe gallery project } E_{41}\end{array}$ & 2 & 2.45 & 1 & 2 & 1.73 & 1.41 \\
\hline & Supplier delivery is not timely $E_{42}$ & 2.45 & 1.73 & 1.41 & 2 & 1 & 2.45 \\
\hline \multirow{3}{*}{ Financial risk $E_{5}$} & $\begin{array}{l}\text { The capital chain was interrupted during the } \\
\text { construction of the pipe gallery } E_{51}\end{array}$ & 2.45 & 3 & 2.83 & 3 & 3.46 & 3.46 \\
\hline & Large changes in interest rates $E_{52}$ & 3.46 & 1.73 & 2 & 2.45 & 3 & 2 \\
\hline & inflation $E_{53}$ & 3.46 & 3.16 & 2.45 & 3 & 3.87 & 3 \\
\hline \multirow{4}{*}{$\begin{array}{l}\text { Project construction and } \\
\text { completion risks } E_{6}\end{array}$} & $\begin{array}{l}\text { Pipe gallery project cannot be completed on time } \\
\qquad E_{61}\end{array}$ & 2.45 & 1.41 & 1.73 & 2.45 & 1.41 & 2.24 \\
\hline & Pipe gallery project cost overrun $E_{62}$ & 2 & 2 & 1.73 & 1.73 & 3.16 & 2.83 \\
\hline & $\begin{array}{l}\text { The pipe gallery project technology is not good } \\
\text { enough } E_{63}\end{array}$ & 2.45 & 2 & 2 & 1.73 & 3.46 & 1.73 \\
\hline & $\begin{array}{l}\text { Excessive design changes of the pipe gallery } \\
\text { project } E_{64}\end{array}$ & 2 & 1.73 & 2 & 3.46 & 2.45 & 3 \\
\hline \multirow{4}{*}{ Technology risk $E_{7}$} & $\begin{array}{l}\text { Construction technology equipment is not } \\
\text { applicable } E_{71}\end{array}$ & 3 & 3.46 & 1.73 & 2.83 & 3 & 2.23 \\
\hline & The technology used is not advanced $E_{72}$ & 1.41 & 1.73 & 2 & 2 & 1.41 & 2.45 \\
\hline & Low resource utilization efficiency $E_{73}$ & 3.46 & 2.83 & 4 & 3.16 & 2 & 2.24 \\
\hline & Inadequate training of construction personnel $E_{74}$ & 3 & 2.45 & 2 & 3.16 & 2.45 & 3.46 \\
\hline \multirow{4}{*}{$\begin{array}{l}\text { Operation management } \\
\text { risk } E_{8}\end{array}$} & $\begin{array}{l}\text { Lack of good communication between all parties } \\
\text { to the project } E_{81}\end{array}$ & 2.83 & 2 & 3 & 2 & 2 & 1.41 \\
\hline & Imperfect management standards $E_{82}$ & 3 & 2 & 1.41 & 2 & 2.45 & 2 \\
\hline & $\begin{array}{l}\text { The maintenance cost of the pipe gallery project } \\
\text { is too high } E_{83}\end{array}$ & 2.83 & 2 & 3.16 & 2.83 & 1.73 & 3.87 \\
\hline & $\begin{array}{l}\text { The equipment is not up to standard after the } \\
\text { handover } E_{84}\end{array}$ & 2.45 & 1.41 & 2.45 & 2.45 & 2 & 4 \\
\hline
\end{tabular}

3.1.4 Form a judgment matrix $X$ according to the risk impact table.

$$
X=\left[\begin{array}{cccc}
x_{1}(1) & x_{1}(2) & \ldots & x_{1}(6) \\
x_{2}(2) & x_{2}(2) & \ldots & x_{2}(6) \\
\ldots & \ldots & \ldots & \ldots \\
x_{25}(1) & x_{25}(2) & \ldots & x_{25}(6)
\end{array}\right]
$$


Find the greatest degree $x_{0}(k)$ of influence from the judgment matrix, use it as a reference value, assign this value to each degree of influence, to form a new matrix $X^{\prime}$.

$$
X^{\prime}=\left[\begin{array}{cccc}
x_{0}(k) & x_{0}(k) & \ldots & x_{0}(\mathrm{k}) \\
x_{1}(1) & x_{1}(2) & \ldots & x_{1}(6) \\
\ldots & \ldots & \ldots & \ldots \\
x_{25}(1) & x_{25}(2) & \ldots & x_{25}(6)
\end{array}\right]
$$

Use the formula $D_{i}=\sum_{k=1}^{6}\left[x_{0}(k)-x_{i}(k)\right]^{2}$ to find the distance value $D_{i}$. After the distance value $D_{i}$ is obtained, the weight of each risk factor $W_{i}$ can be obtained by using $W_{i}=\frac{1}{1+D_{i}}$. Normalize the obtained weight value to get the final weight result $W_{i}^{\prime}$.

$$
W_{i}^{\prime}=(0.1884,0.0703,0.1186,0.0272,0.0185,0.0174,
$$
$0.0135,0.0299,0.0187,0.0195,0.0490,0.0287,0.0542$, $0.0210,0.0252,0.0248,0.0287,0.0355,0.0197,0.0420$, $0.0373,0.0246,0.0238,0.0351,0.0282$ )

\subsubsection{Result analysis}

Among all risk factors, political and legal risks have the largest weights, and three of the second-level indicators also have the top three weights. As the urban underground comprehensive pipeline corridor PPP project has a certain public welfare, social capital investment is large, and the social capital needs the support of the government when participating in the cooperation process, so the government's credit and the degree of intervention have a huge impact on the project. The project construction and completion risk is the second and the technical risk is the third. The project construction and completion risk is the second and the technical risk is the third. There are many participants in the PPP project of the urban underground comprehensive pipeline corridor, the construction and operation cycle is longer, and there are more uncertain factors than ordinary construction projects, so risks are more likely to occur during the construction period and the operation period. Financing completion risk and approval delay risk ranked fourth and fifth respectively. If the funds are not available for a long time, there will be a risk of project shutdown.

\section{Conclusion}

4.1.1 The improved gray correlation analysis model is used to analyze the risk sharing mechanism of the PPP project of the urban underground comprehensive pipeline gallery, and the following conclusions are drawn.

4.1.2 Using the work structure decomposition method, the 25 risk factors faced by the participants of the urban underground comprehensive pipeline corridor PPP project project are obtained. The principle of risk sharing based on the PPP model of the urban underground comprehensive pipe gallery project is discussed, the risk sharing model is constructed using improved grey relational analysis, and the best risk-bearer is selected by the method of quantitative analysis.

4.1.3 The gray correlation evaluation method is conducive to the quantitative evaluation of urban underground comprehensive pipeline corridor PPP projects from multiple dimensions. Through further quantitative analysis, it can basically achieve horizontal comparison of the same market indicators during the same period, and the overall transaction conditions of different markets during the same period. The transactions in the same market during different periods are vertically comparable, providing data support for the subsequent construction and supervision of the PPP project of the urban underground comprehensive pipeline gallery.

\section{Acknowledgment}

The authors' special thanks go to all reviewers of the paper and data support from the government and social capital cooperation center.

\section{References}

1. Ke Yongjian, Wang Shouqing, and Chen Bingquan, The Enlightenment of the Failure of the Channel Tunnel to PPP Project Risk Sharing, China Civil Engineering Journal, 2008 (12), pp.97-102.

2. Cheng Chen, Michael Hubbard. Power relations and risk allocation in the governance of public private partnerships: A case study from China, Policy and Society, 2012,31(1).

3. Martinus P. Abednego,Stephen O. Ogunlana. Good project governance for proper risk allocation in public-private partnerships in Indonesia, International Journal of Project Management,2006,24(7).

4. Li Shouguo, Zhou Wenjun, Analysis of Risk Sharing Mechanism of Underground Comprehensive Pipe Gallery Project Based on PPP Model, Journal of Safety and Environmentl, 2018,18 (03) , pp.10191024.

5. Cui Jie, Dang Yaoguo, and Liu Sifeng, An Improved Method for Solving Index Weight Based on Grey Incidence, China Management Science, 2008 (05), pp.141-145. 